\title{
Quality Control of Emergency Dental Care in Mures County
}

\author{
KINGA DORNER ${ }^{1}$, BERNADETTE KEREKES-MATHE ${ }^{2}$, MELINDA KIS $^{3}$, ANDREEA BORS ${ }^{4}$, \\ CRISTINA MOLNAR-VARLAM ${ }^{5}$, VANDA ROXANA NIMIGEAN ${ }^{6 *}$, VICTOR NIMIGEAN ${ }^{7}$, \\ MELINDA SZEKELY ${ }^{8}$ \\ ${ }^{1}$ University of Medicine and Pharmacy, Science and Technology Targu-Mures, Faculty of Dental Medicine, Department of \\ Removable Prosthetic Dentistry, 38 Gh.Marinescu Str, 540139, Tirgu-Mures, Romania \\ ${ }^{2}$ University of Medicine and Pharmacy, Science and Technology Targu-Mures, Faculty of Dental Medicine, Department of \\ Morphology of Teeth and Dental Arches; Technology of Dental Prosthesis and Dental Materials, 38 Gh.Marinescu Str., \\ 540139, Tirgu-Mures, Romania \\ ${ }^{3}$ CMI Cabinet Stomatologic Dr. Nagy Imre, 1 Savinestilor Str., 410432, Oradea, Romania \\ ${ }^{4}$ University of Medicine and Pharmacy, Science and Technology Targu-Mures, Faculty of Dental Medicine, Department of \\ Morphology of Teeth and Dental Arches; Technology of Dental Prosthesis and Dental Materials, 38 Gh.Marinescu Str., \\ 540139, Tirgu-Mures, Romania \\ ${ }^{5}$ University of Medicine and Pharmacy, Science and Technology Targu-Mures, Faculty of Dental Medicine, Department of \\ Morphology of Teeth and Dental Arches; Technology of Dental Prosthesis and Dental Materials, 39 Gh.Marinescu Str., \\ 540139, Tirgu-Mures, Romania \\ ${ }^{6}$ Carol Davila University of Medicine and Pharmacy in Bucharest, Faculty of Dental Medicine, Department of Oral \\ Rehabilitation, 17-23 Calea Plevnei, 010221, Bucharest, Romania \\ ${ }^{7}$ Carol Davila University of Medicine and Pharmacy in Bucharest, Faculty of Dental Medicine, Department of Anatomy, \\ 17-23 Calea Plevnei Str., Bucharest, Romania \\ ${ }^{8}$ University of Medicine and Pharmacy, Science and Technology Targu-Mures, Faculty of Dental Medicine, Department of \\ Morphology of Teeth and Dental Arches; Technology of Dental Prosthesis and Dental Materials, 38 Gh.Marinescu Str., \\ 540139, Tirgu-Mures
}

Satisfaction of dental patients is an indicator of the quality of dental health care, and it is a patientbased outcome measure. The main objective of this four-year retrospective questionaire based study was to assess the satisfaction of patients who attended the Dental Emergency Medical Office at Mobile Emergency Service for Resuscitation and Extrication Tirgu Mures between 2014-2017. A total of 909 questionnaires were completed in the analyzed four-year period. The average value of staff scoring, waiting time to take over by the medical staff, doctor's time for consultation, the clarity of information received about investigations and medical procedures performed lead to a satisfaction percentage of $95.2 \%$ The score on the quality of the received medical services resulted in a satisfaction rate of $95.6 \%$ The results of the study confirmed the necessity of setting up this type of dental office that is available to all those affected by dental diseases requiring emergency treatment.

Keywords: satisfaction, dental emergency treatment, retrospective questionnaire-based stud

Tooth pain, negligence and fear of dental interventions are common characteristics in Romanian population. These are the main causes for postponing and avoiding necessary dental treatments, with serious consequences on the dental state of the individual and the community [1].

The Mobile Emergency Service for Resuscitation and Extrication (MESRE) is operating as a part of the Mures County Emergency Hospital in Tirgu Mures. The MESRE was conducted between 1990 and 1993 on voluntary bases. Similar services have been established in the whole country, where the patients received free of charge dental services. The implementation of an Emergency Dental Office as part of MERSE was of almost importance because dental emergency services were not provided for 24 hours as a non-stop service.

Due to multiple requests, on $1^{\text {st }}$ of February 2012 the MESRE Emergency Dental Office of Tirgu Mures was established according to the Ordinance No. 1706/2 ${ }^{\text {nd }}$ October 2007 of the Ministry of Health regarding the administration and organization of units and departments of dental emergencies [2, 3].

Satisfaction of dental patients is an indicator of the quality of dental health care, and it is a patient-based outcome measure. Patients can identify areas for improvement and address users' needs, like waiting time [4].

Meeting patients' expectations by taking time to understand the needs and giving the right instructions is associated with higher satisfaction [5].

*email: vandanimigean@yahoo.com; Phone: +40721561848

REV.CHIM.(Bucharest) $\bullet 70 \diamond$ no.12 2019 
In accordance with the quality management system SR EN ISO 9001: 2008 regarding the appreciation of the medical services and the improvement of their quality, both in the General Emergency Receipt Unit and in the Emergency Dental Office patient satisfaction assessment questionnaires were introduced. The data were collected was in order to evaluated to improve the dental health system in emergency dental care.

The main objective of our four-year retrospective study was to assess the satisfaction of patients who attended the Dental Emergency Medical Office at MESRE Tirgu Mures between 2014-2017, using a self-administered questionnaire.

\section{Experimental part}

In this questionnaire-based study, we have statistically processed non-personal data over a four-year period. The methodology of the study was retrospective, descriptive, based on the analysis of the questionnaires completed by randomly selected patients out of the patients treated in the Emergency Dental Office at MESRE Tirgu Mures between $1^{\text {st }}$ of January 2014 and $31^{\text {st }}$ of December 2017. Our sample consisted of the completed questionnaires.

In this study we aimed to determine the satisfaction level of the patients according to the used questionnaire with grades from 1 to 5, from very dissatisfied to very satisfied, assessing this way the quality of the received medical services. Grade 5 represented the $100 \%$ satisfaction of patients or caregivers (in case of helpless children or elderly patients) (Fig.1).

The questionnaire consisted of two parts. The questions in the first part of the questionnaire were referred to the way patients perceive their dental treatments. The second part of the questionnaire addresses the delicate subject of the patient's situation if it was necessary (or not) to offer additional attention to receive quality medical services, as well as observations and suggestions from patients about the future development of the service (Fig. 1).

In accordance to the quality management system SR EN ISO 9001: 2008 regarding the appreciation of the medical services and the improvement of their quality, please answer the quentions below.

Answer the questions by checking the box that describes your current situation, and complete the rows adding the suggestions and comments regarging our collaboration.

\begin{tabular}{|c|c|c|c|c|c|c|}
\hline \multirow{2}{*}{\multicolumn{2}{|c|}{ Questions }} & \multirow{2}{*}{\multicolumn{5}{|c|}{ Qualifing/Mark }} \\
\hline & & & & & & \\
\hline & & \multirow{3}{*}{\begin{tabular}{l|}
$\begin{array}{l}\text { Very } \\
\text { dissatisfied }\end{array}$ \\
1 \\
\end{tabular}} & \multirow{3}{*}{$\begin{array}{c}\text { Dissatisfied } \\
2 \\
\end{array}$} & \multirow{3}{*}{$\begin{array}{r}\text { Satisfied } \\
3 \\
\end{array}$} & \multirow{3}{*}{$\begin{array}{r}\text { Pleased } \\
4 \\
\end{array}$} & \multirow{3}{*}{$\begin{array}{l}\begin{array}{l}\text { Very } \\
\text { pleased }\end{array} \\
5 \\
\end{array}$} \\
\hline & & & & & & \\
\hline 1 & $\begin{array}{l}\text { How satisfied are you with the } \\
\text { promptness you were treated? }\end{array}$ & & & & & \\
\hline 2 & $\begin{array}{l}\text { How satisfied are you with the } \\
\text { amiability of the personnel whom you } \\
\text { were in contact with? }\end{array}$ & & & & & \\
\hline 3 & $\begin{array}{l}\text { How satisfied are you with the waiting } \\
\text { time until you have been taken over } \\
\text { by the medical personnel? }\end{array}$ & & & & & \\
\hline 4 & $\begin{array}{l}\text { How satisfied are you with the time } \\
\text { accorded for your consultation? }\end{array}$ & & & & & \\
\hline 5 & $\begin{array}{l}\text { How satisfied are you with the quality } \\
\text { of the recevied care? }\end{array}$ & & & & & \\
\hline 6 & $\begin{array}{l}\text { How satisfied are you with the quality } \\
\text { of the information about the } \\
\text { investigations and procedures that } \\
\text { were applied? }\end{array}$ & & & & & \\
\hline 7 & $\begin{array}{l}\text { How satisfied are you with the clarity } \\
\text { of the information recevied about the } \\
\text { treatment and recommendations that } \\
\text { has to be followed in the next period? }\end{array}$ & & & & & \\
\hline 8 & $\begin{array}{l}\text { What do you think about the } \\
\text { organization MESRE? }\end{array}$ & & & & & \\
\hline 9 & $\begin{array}{l}\text { What do you think about the } \\
\text { cleanliness? }\end{array}$ & & & & & \\
\hline 10 & What is your general impression? & & & & & \\
\hline
\end{tabular}

For receiving good quality medical services you were constrained to offer gifts: YES/NO

If yes, please mention the name or the function of this person.

Comments and suggetions for improvement of the acitvity of MESRE:

Fig. 1. Patient satisfaction survey questionnaire 
The results obtained were processed according to the Monthly / Yearly Patient Satisfaction centralizer.

\section{Results and discussions}

A total of 909 questionnaires were completed in the analyzed four-year period. The distribution of the number of evaluated questionnaires over the years studied on patient satisfaction is shown in Fig. 2. The average values of satisfaction during the study period is shown in Fig. 3.

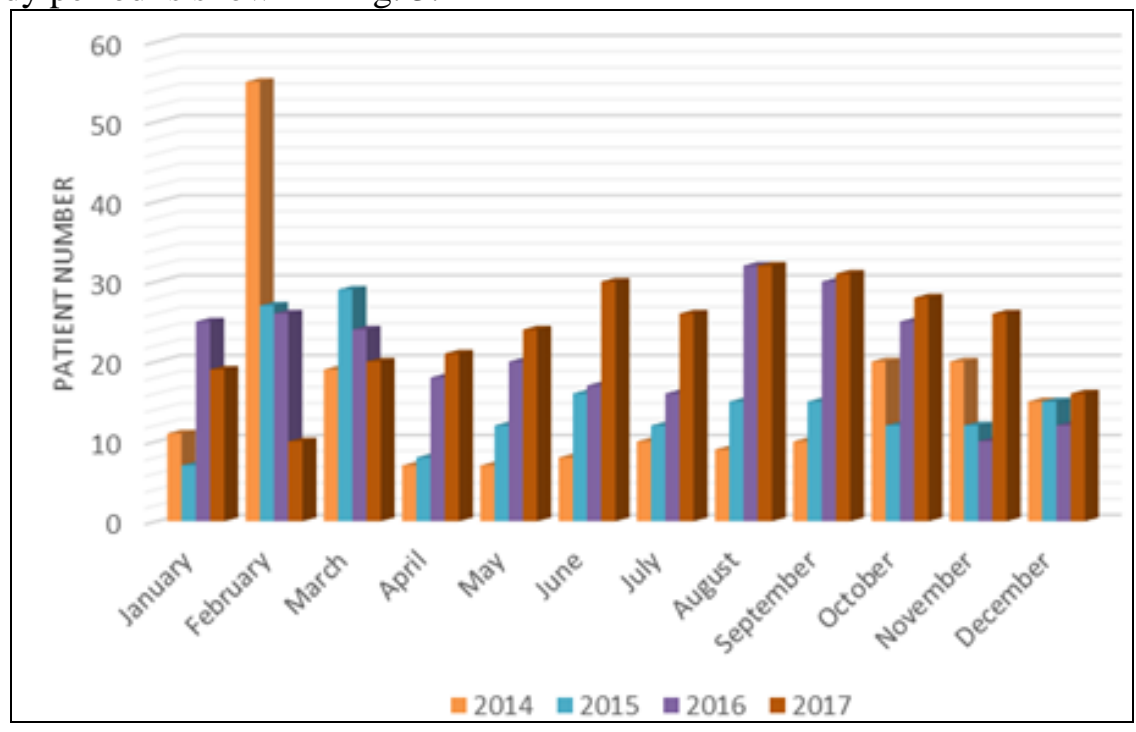

Fig. 2. Prevalence of patients who completed the satisfaction questionnaire according to the months and years of the investigated period

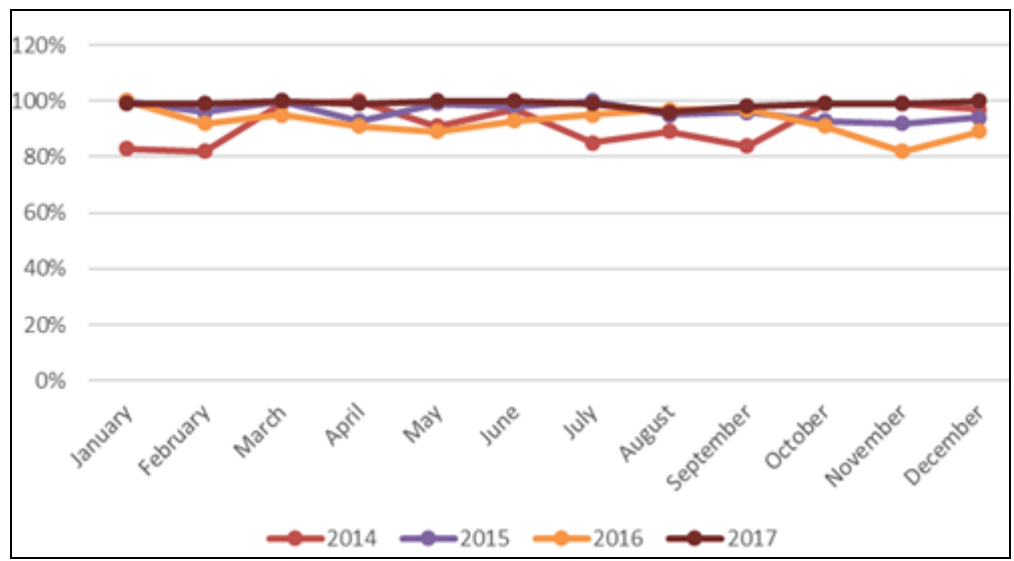

Fig. 3. Degree of patient satisfaction over the studied years

The average value of staff scoring, waiting time to be taken over by the medical staff, time spent with consultation, the clarity of information received about investigations and medical procedures performed lead to a satisfaction percentage of 95.2\% (Fig. 4).

The score on the quality of the received medical services resulted in a satisfaction rate of $95.6 \%$ (Fig.4).

The score on the clarity of the information on the recommendations and the treatment to be followed resulted in a $95 \%$ satisfaction percentage (Fig. 4).

The general satisfaction percentage for cleanliness on the emergency dental office corresponds to a 96.4\% (Fig. 4).

The lowest satisfaction scores were observed in 2014 and 2016, while the highest scores were recorded in 2015 and 2017. 


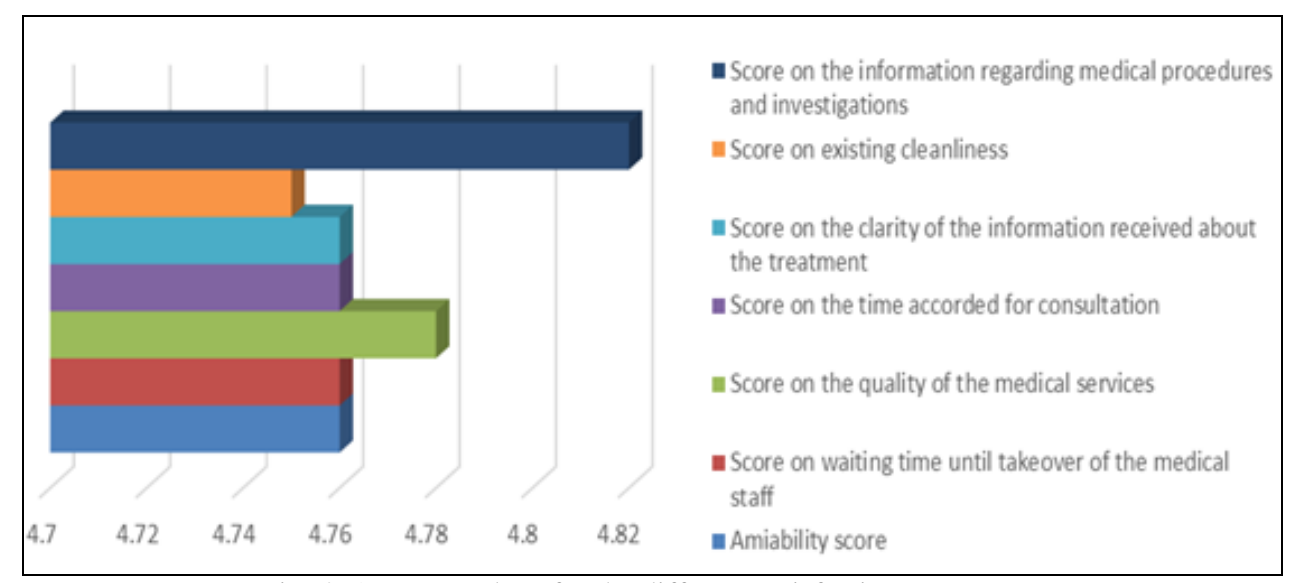

Fig. 4. Average values for the different satisfaction parameters

Regarding the second part of the administered questionnaire, none of the interviewed patients included in the study stated that they had given attention or "gifts" to get good quality medical services.

There was only one suggestion of improvement on the endowment of the medical cabinet, and no complaint was made.

Concerning the satisfaction regarding the medical services offered by the Emergency Dental Office over the investigated period four years, the patients were almost very satisfied with an average of $93.75 \%$ (Fig. 3).

Satisfaction, through good advice and effective reassurance, can not only lead to better compliance with subsequent care, but may also encourage more confident self-care or more informed care-seeking in the future [6].

Most patients attending emergency dental services expressed overall satisfaction, and very few expressed dissatisfaction. With any 'measure' of patient satisfaction it is difficult to define what scores warrant the label 'dissatisfaction' or 'satisfaction', or the proportion of dissatisfied patients that would require prompt action to improve services [7].

Dental emergency includes different types of interventions, some can even be lifesaving. Although there is a list of procedures that can be used in the case of dental emergencies and these are also included in the Order of the Ministry of Health (No. 1706 of 2017, respectively article 1523 of 2008), it is difficult to differentiate dental pathologies requiring an emergency response from those that may be delayed and not treated in emergency $[8,9]$. Patients are taking advantage of this and resorting to free 24-hour services, invoking the unbearable pain. Although, the data gathered from the dental emergency office database does not reflect the real situation of emergencies being affected by social issues. It should also be considered that patients may present at the same time several systemic diseases and dental conditions, so different symptoms overlap, causing confusion of patients and may mislead unexperienced medical staff $[10,11,12]$.

The reason for attending to the dental emergency office is dominated by pain due to dental problems or their complications (septic processes, haemorrhages, etc.) and accidents due to various reasons (road, sports or dental treatment). During the recording of medical history, the dentist must show empathy towards the patient, ensuring patient compliance and the effectiveness of emergency intervention. The professionalism of the dentist providing emergency care physician should lead to the exclusion of iatrogenic injuries in the dental intervention [13].

The management of the quality of the medical act in dental emergency is evaluated by the authorities authorized by the legislation in force, from a professional point of view. Patients, however, are sensitive not only to the quality of the treatments received, but also to the behaviour of dentists and dental assistants, as well as to the nature of the information provided by healthcare professionals. Both, adult patients and children, appreciate the most the quality of interpersonal relationships during dental treatments, especially in emergency dental procedures. Communication between the dentist and the patient is the most important factor in obtaining the patient's satisfaction [14].

In the Emergency Dental Office as MESRE in Tirgu Mures the patient satisfaction questionnaires have been filled in since 2014. As required by the Ministry of Health, completion of these questionnaires has become mandatory since February 2015 for all hospital units [15].

In 2017 a similar survey was conducted in MESRE regarding the general medical care and the results showed a lower grade of satisfaction (82\%). A total of 711 patients answered the questions of the same questionnaire. They were complaining about the waiting time, the lack of cleanliness of the sanitary groups and the waiting room, and also the deficiency of parking places. 
A similar study was conducted in Romania also in Sibiu between the $1^{\text {st }}$ of September 2016 and the $30^{\text {th }}$ of October 2016. According to the results obtained with the services provided in a similar dental emergency office in Sibiu, it was found that more than half of the patients were satisfied with the treatment received, almost all were satisfied with the behaviour of the medical staff and most of them stated that the dentists who treated them were trustworthy. Nearly half of the patients mentioned that improvements on the endowment of the dental office could not be observed [16, 17].

Batbaatar and colab. reported in their systematic review that interpersonal care factors like friendliness, caring, and sympathy are the most common determinants associated with satisfaction in the available publications [18]. In order to build up an appropriate relationship with the patients by asking in addition about his or her general health status, giving him or her enough time to communicate with the medical staff, was associated with higher satisfaction. This is a simple method that has been shown to increase patient satisfaction in Brazilian dental and medical settings and also helps the dental staff to meet the patients' needs and expectations $[19,20]$. Kikwilu and colab. reported that the satisfaction of patients from Tanzania was associated with the cleanliness of the dental clinic [21]. Anderson conducted a study based on a qualitative interview instead of a questionnaire. It was assumed that many emergency dental attenders want advice from the dentist as much as relief from pain [7]. These findings are in accordance with our results.

\section{Conclusions}

The Emergency Dental Office included in the present study is highly requested, with high addressability among the population of Mures County.

The results of the study confirmed the necessity of setting up this type of dental office that is available to all those affected by dental diseases requiring emergency treatment.

The values obtained by applying the satisfaction questionnaire to the patients who received dental emergency services showed a high level of satisfaction.

The quality of the medical interventions was ensured through the efficient organization of the emergency reception unit, the promptness of the interventions, the professionalism of the personnel serving this unit, as well as the proper behaviour towards the patients, appreciated by the investigated persons.

Data evaluation has led to favourable outcomes, however these have to be interpreted with care, as questionnaire-based studies imply a higher degree of subjectivity. However, the random way in which the subjects were chosen provides to our results a value in terms of epidemiological research, offering a modest contribution to the current state of knowledge, in the domain of quality assessment of emergency dental care.

\section{References}

1.GYERGYAY, R., SZEKELY, M., MARTHA, K., POP, S.I., Epidemiological survey of dental fear and anxiety in Romanian children living in Hungary. Medicine in Evolution, 20(1), 2014, 121-9.

2.DORNER, K., BOERIU, C., VASS, H., NAGY, M., KOSZTA, Z.S., IURCOV, R., SZEKELY, M., Comparative Study Regarding Activity of Emergency Dental Offices in Tirgu-Mures and Oradea. Acta Medica Marisiensis, 61(2), 2015, 118-21.

3.DORNER, K., KIS, M., MARKOVICS, E., BIRTA, O., KOSZTA, Z., BOERIU, C., VASS, H., SZEKELY, M., A Two-year Retrospective Study of Emergency Dental Treatments at Mures County Emergency Hospital. Journal of Interdisciplinary Medicine, 2(1), $2017,25-30$.

4.DONABEDIAN, A., The quality of care: How can it be assessed? Jama, 1988, 260, 1743-8.

5.ALDOSARI, M.A., TAVARES, M.A., MATTA-MACHADO, A.T.G., ABREU, M.H.N.G., Factors associated with patients' satisfaction in Brazilian dental primary health care. Research article. PLoS ONE 12(11):e0187993. https://doi.org/10.1371/journal.

6.LOCKER, D., DUNT, D., Theoretical and methodological issues in sociological studies of consumer satisfaction with medical care. Soc. Sci. Med., $1988,12,283-92$.

7.ANDERSON, R., THOMAS, D.W., PHILLIPS, C.J., The effectiveness of out-of-hours dentalservices: II. patient satisfaction. British Dental Journal, 2005, 198(3), 151-6.

8.***http://www.smurd.ro/multimedia/pdf/legislatie/31-03-2010-ordin-1706.2007.pdf

9.***http://www.cnas.ro/national-page/hotarare-nr-400.html

10.NEMES-NAGY E., FAZAKAS Z., BALOGH-SAMARGHITAN V., SIMON-SZABO Z.S., DENES L., UZUN C., FODOR M.F., DOBREANU M., TILINCA M., REID D., HIGGINS T., Comparison of five chromatographic methods used for glycated hemoglobin measurement. Revista Romana de Medicina de Laborator, 2016, 24(4), 431-9.

11.TILINCA M.C., PAL S., PREG Z., BARABAS-HAJDU E., TILINCA R., GERMAN-SALLO M., NEMES-NAGY E., The relationship of metabolic and endocrine parameters with associated diseases in diabetes mellitus. Rev. Chim. (Bucharest), 69, 2018, no.5, p.1288-91.

12.TILINCA M.C., BARABAS-HAJDU E., TUSA-FERENCZ G., NEMES-NAGY E., Involvement of inflammatory cytokines in obesity and its complications. Revista Romana de Medicina de Laborator, 2018, 26(3), 359-72.

13.IEREMIA, L., BRATU, D., NEGRUTIU, M., Metodologia de examinare in protetica dentara. Ed. SIGNATIA Timisoara 2000; 30-40.

14.SZEKELY, M., Az orvosi kommunikacio szerepe a fogaszatban. Ed. University Press Tirgu Mures 2005; 70-88.

15.***Articolul 20 alin (2) din legea 185/2017 privind asigurarea calitatii in sistemul de sanatate. 
16.TANTAR, C.A., Research on increasing the efficiency of the Emergency Dental Office of the Emergency Room within the County Clinical Emergency Hospital of Sibiu. PhD Thesis, University „Lucian Blaga” of Sibiu 2017, (Resume).

17. DORNER, K., KEREKES-MATHE, B., BORS, A., MOLNAR-VARLAM, C., NIMIGEAN, V.R., SZEKELY, M., Patients Attendance for Emergency Dental Services in Mures County, Rev. Chim. (Bucharest), 69, no. 8, 2018, p. 2115-20

17.DORNER, K., KEREKES-MATHE, B., BORS A., MOLNAR-VARLAM C., NIMIGEAN V.R., SZEKELY M., Patients Attendance for Emergency Dental Services in Mures County, Rev. Chim. (Bucharest), 2018, 69(8), 2115-20.

18.BATBAATAR, E., DORJDAGVA, J., LUVSANNYAM, A., SAVINO, M.M., AMENTA, P., Determinants of patient satisfaction: a systematic review. Perspect Public Health, 2017, 137, 89-101.

19.RAHMQVIST, M., BARA, A.C., Patient characteristics and quality dimensions related to patient satisfaction. Int. J. Qual. Health Care, 2010, 22, $86-92$.

20.BJERTNAES, O.A., SJETNE, I.S., IVERSEN, H.H., Overall patient satisfaction with hospitals: effects of patientreported experiences and fulfilment of expectations. BMJ Qual. Saf., 2012, 21, 39-46.

21.KIKWILU, E.N., KAHABUKA, F.K., MASALU, J.R., SENKORO, A., Satisfaction with urgent oral care among adult Tanzanians. J. Oral Sci., $2009,51,47-54$

$\overline{\text { Manuscript received: } 24.04 .2019}$ 